\title{
A Method for Determination of Metals in Hybrid Metal Oxide/Metal-Carbon Nanotubes Catalysts
}

\author{
Joanna Bok-Badura, ${ }^{1}$ Agata Jakóbik-Kolon, ${ }^{1}$ Agata Lamacz, ${ }^{2}$ and Krzysztof Karoń ${ }^{3}$ \\ ${ }^{1}$ Department of Inorganic, Analytical Chemistry and Electrochemistry, Faculty of Chemistry, Silesian University of Technology, \\ Bolesława Krzywoustego 6, 44-100 Gliwice, Poland \\ ${ }^{2}$ Division of Chemistry and Technology of Fuels, Wroclaw University of Technology, Wroclaw, Poland \\ ${ }^{3}$ Department of Physical Chemistry and Technology of Polymers, Faculty of Chemistry, Silesian University of Technology, \\ Marcina Strzody 9, 44-100 Gliwice, Poland \\ Correspondence should be addressed to Agata Jakóbik-Kolon; agata.jakobik@polsl.pl
}

Received 5 September 2016; Revised 14 December 2016; Accepted 4 January 2017; Published 18 January 2017

Academic Editor: Cristina Femoni

Copyright (C) 2017 Joanna Bok-Badura et al. This is an open access article distributed under the Creative Commons Attribution License, which permits unrestricted use, distribution, and reproduction in any medium, provided the original work is properly cited.

Carbon nanotubes (CNTs), due to their special structure and unique properties, are still one of the most interesting materials for scientists. Recently, carbon nanotubes were proposed as a new type of carbon support for catalysts. Fe, Pt, Ni, Co, and other metals anchored to CNTs are used in various reactions. Due to the fact that production processes are usually unpredictable and the total amount of metal/metal oxide deposited on the CNTs may only be estimated, the methods for examining the chemical composition are necessary. In this study, fast and simple inductively coupled plasma atomic emission spectrometry (ICP-AES) with slurry nebulization was proposed for metal content determination in hybrid $\mathrm{CeZrO}_{2} / \mathrm{CNT}, \mathrm{Ni}-\mathrm{CeZrO} 2 / \mathrm{CNT}$, and Ni/CNT materials. Slurries were prepared by $30 \mathrm{~min}$ ultrasonication of appropriate amount of investigated material in $1 \%$ Triton X-100 solution. Optimal range of slurry concentration and optimal RF plasma power were established (40-400 $\mathrm{mg} \mathrm{L}^{-1}, 1.2 \mathrm{~kW}$, resp.). Obtained results proved that this method may be applied for determination of $\mathrm{Ce}, \mathrm{Zr}$, and $\mathrm{Ni}$ in hybrid CNT-based materials.

\section{Introduction}

Carbon nanotubes (CNTs), due to their particular structure and exceptional properties (optical, electrical, magnetic, and mechanical), are still one of the most interesting materials for scientists. They may find an application in power and material engineering, electronics, medicine, and biotechnology [14]. Recently, carbon nanotubes were also proposed as a new type of catalyst support. $\mathrm{Pt}, \mathrm{Fe}, \mathrm{Ni}, \mathrm{Co}$, and other metals anchored to CNTs are used in various reactions (e.g., preferential oxidation of CO (PROX), water gas shift (WGS), hydrogenation of unsaturated hydrocarbons, dehydrogenation of alkanes, hydrogen and methanol oxidation, or steam reforming of hydrocarbons or alcohols [5-8]). To prepare carbon nanotubes supported catalysts, several methods, such as organometallic grafting, electron beam evaporation, deposition/precipitation, ion-exchange, and incipient wetness impregnation, were proposed [5]. Obtained hybrid materials are usually characterized using scanning and transmission electron microscopy (SEM, TEM), thermogravimetric analysis (TGA), elemental analysis (EA), Raman Spectroscopy (RS), and temperature-programmed methods. Unfortunately, most of these methods are applicable only for analysis of the dispersion of the metals on the CNT walls or semiquantitative analysis of metal concentration. They usually provide only information about the content of nonvolatile or noncombustible part of the sample. More detailed studies are possible if the ICP-AES or ICP-MS is used. However, in experiments described so far, the digestion of CNTs is required [9]. Due to the fact that digestion of CNT is extremely difficult, it constitutes the most problematic step in whole analysis.

In the present work we propose a fast and simple method of direct determination of metals contained in the CNTbased materials, based on ICP-AES analysis with slurry nebulization. This method has been previously successfully 
TABLE 1: The operating parameters of ICP-AES analysis.

\begin{tabular}{lc}
\hline Parameter & Value \\
\hline RF power, $\mathrm{kW}$ & 1.2 \\
Ar plasma flow rate, $\mathrm{L} \mathrm{min}^{-1}$ & 15 \\
Ar carrier flow rate, $\mathrm{L} \mathrm{min}^{-1}$ & 1.5 \\
Nebulizer pressure, $\mathrm{kPa}$ & 210 \\
Pump rate, rpm & 15 \\
Viewing & Axial \\
& $380.153,413.380,444.933$, \\
Ce wavelength, $\mathrm{nm}$ & $546.021,456.236,459.393$, and \\
& 527.423 \\
Zr wavelength, $\mathrm{nm}$ & $256.889,257.143,267.865$, \\
& $284.458,327.307,339.198$, \\
Ni wavelength, $\mathrm{nm}$ & $343.823,349.619$, and 444.301 \\
\end{tabular}

used for determination of iron in multiwall carbon nanotubes (MWCNTs) [10]. The main advantage of this method is simple sample preparation protocol which does not require laborious and time-consuming digestion of examined material. Moreover, this method is simple to implement and the modification of ICP-AES apparatus is not required.

\section{Experimental}

2.1. Apparatus. All measurements of metals concentration were accomplished using ICP-AES apparatus (Varian 710ES spectrometer equipped with a V-groove nebulizer and a reduced-volume Sturman-Masters type spray chamber made of poly(tetrafluorethylene)-Varian). In Table 1 all operating parameters of analysis and all selected analytical lines are summarized.

Characterization of examined materials was performed using SEM (scanning electron microscope-Phenom Pro Desktop SEM).

2.2. Materials and Reagents. In this work, three types of hybrid CNT materials were used: $\mathrm{CeZrO}_{2} / \mathrm{CNT}, \mathrm{Ni} / \mathrm{CNT}$, and $\mathrm{Ni}-\mathrm{CeZrO} \mathrm{Z}_{2} / \mathrm{CNT}$. Prior to deposition of metal $(\mathrm{Ni})$ or metal oxide $\left(\mathrm{CeZrO}_{2}\right)$, the multiwall CNTs (Aldrich) were functionalized in $\mathrm{HNO}_{3}$; next, the method of hybrid material preparation was as follows.

The Ni/CNT catalyst was obtained via wet impregnation of CNTs with nickel nitrate. The CNTs with ethanol were placed in a three-necked flask connected with a reflux condenser and sonicated for 5 minutes in an ultrasound bath. Next, the $\mathrm{Ni}\left(\mathrm{NO}_{3}\right)_{2}$ water solution was instilled to the CNTs suspension. The synthesis was conducted under flowing Ar. After one hour, the $\mathrm{NaOH}$ solution was instilled to the CNTs suspension until its $\mathrm{pH}$ was 10 . The solution was stirred using a magnetic stirrer. The mixture was then placed, heated to $70^{\circ} \mathrm{C}$, and remained at this temperature for 4 hours. Afterwards, the solution was stirred overnight at room temperature. The resulting material was filtered and washed with deionized water until the filtrate was neutral. The product was dried overnight at $120^{\circ} \mathrm{C}$ and calcined for 2 hours at $700^{\circ} \mathrm{C}$ in flowing Ar. As-prepared material was reduced in $\mathrm{H}_{2} / \mathrm{Ar}$ at $700^{\circ} \mathrm{C}$ for 2 hours.

Synthesis of $\mathrm{CeZrO}_{2} / \mathrm{CNT}$ was as follows: functionalized CNTs and acetone were placed in a three-necked flask connected with a reflux condenser. The mixture was sonicated for 10 minutes. Water-acetone $(1: 1)$ solutions of $\mathrm{Ce}\left(\mathrm{NO}_{3}\right)_{3} \cdot 6 \mathrm{H}_{2} \mathrm{O}$ and $\mathrm{ZrO}\left(\mathrm{NO}_{3}\right)_{2} \cdot x \mathrm{H}_{2} \mathrm{O}$ were prepared and instilled to CNTs suspension in acetone. The suspension was placed in an ultrasonic bath for 35 minutes. Afterwards, the $1 \mathrm{M} \mathrm{NaOH}$ was instilled until the mixture $\mathrm{pH}$ was 10 . The suspension was constantly stirred and placed in a water bath at $70^{\circ} \mathrm{C}$ for 4 hours. Next it was stirred overnight at room temperature. The synthesis was carried out under flowing Ar. The resulting hybrid material was filtered and washed with deionized water until the filtrate was neutral. In the final step the material was dried at $120^{\circ} \mathrm{C}$ overnight and calcined at $700^{\circ} \mathrm{C}$ for 2 hours under flowing Ar.

The Ni-CeZrO ${ }_{2} / \mathrm{CNT}$ hybrid material was obtained by impregnation of CNTs with corresponding nitrates.

Slurries were prepared using Triton X-100 (SigmaAldrich) as a dispersing agent according to the procedure described in literature $[10,11]$. Nitric acid (65\%, Suprapur, Merck) was used in leaching studies. In all experiments ultrapure water (Millipore Elix 10 System) was used.

\subsection{Procedures}

2.3.1. ICP-AES Sample Preparation. Proper amounts of examined materials were accurately weighed and next ultrasonicated (ultrasonic bath Grant XUB 5, 32-38 kHz, $150 \mathrm{~W}$, and $70^{\circ} \mathrm{C}$ ) in the $1 \%$ Triton $\mathrm{X}-100$ solution for 30 minutes. Ultrasonication in Triton X-100 solution purposed to ensure adequate dispersion and obtain homogeneous slurry.

2.3.2. Calibration. Calibration curves for ICP-AES analysis were established with standard solution of $\mathrm{Ce}, \mathrm{Ni}$ (Merck, $1 \mathrm{mg} \mathrm{mL}^{-1}$ in $2 \% \mathrm{HNO}_{3}$ ), and $\mathrm{Zr}$ (Merck, $10 \mathrm{mg} \mathrm{mL}^{-1}$ in $2 \% \mathrm{HNO}_{3}$ ) in $1 \%$ Triton $\mathrm{X}-100$ or in nitric acid of proper concentration (leaching studies). Triton X-100 was used for standards preparation to ensure the same matrix effect as that may occur in the samples. Liquid standards could be used in slurry examination with assuming that at some condition the transportation of slurry is similar to the aqueous solution transportation. Standards for preliminary studies were prepared in the range of 0.1 to $70 \mathrm{mg} \mathrm{L}^{-1}$ for each metal.

\subsubsection{Effect of Slurry Concentration on Determination of Ce-} rium, Zirconium, and Nickel. Based on previously described experiment the range of slurries concentration to be tested was established as 40 to $400 \mathrm{mg} \mathrm{L}^{-1}$ [10]. To investigate the effect of slurry concentration on $\mathrm{Ce}, \mathrm{Zr}$, and $\mathrm{Ni}$ determination, three parallel samples of various slurries concentration were prepared by dilution of the primary slurries. Concentration of the metals in these slurries was measured by ICP-AES under conditions presented in Table 1. Obtained results were 
computed as the mean values from the calibration curves obtained for all applied analytical lines.

2.3.4. Effect of RF Plasma Power on Determination of Cerium, Zirconium, and Nickel. Additionally, effect of the RF plasma power on $\mathrm{Ce}, \mathrm{Zr}$, and $\mathrm{Ni}$ determination was examined. For this purpose, the previously prepared standards and samples (100 $\mathrm{mg} \mathrm{L}^{-1}$ slurries concentration) were analyzed using the $1.4 \mathrm{~kW}$ RF plasma power. All analytical parameters were the same as in Table 1, except the Ar plasma flow rate and carrier flow rate, which were established as 16.5 and $1.7 \mathrm{~L} \mathrm{~min}^{-1}$, respectively.

2.3.5. Leaching Studies. As mentioned previously, the complete digestion of investigated material is very difficult or even impossible, so obtaining clear solution and the direct determination of metals in aqueous solution could not be conducted. Therefore, some leaching studies were provided to check the possibility of quantitative elution of metals from investigated catalysts. Metals were leached from the CNTs based materials using 5\% and $67 \%$ nitric acid solutions. All samples before leaching studies were dispersed in the $1 \%$ Triton X-100 solution. Amount of metals in obtained leachates was measured by ICP-AES method using standards prepared with the appropriate matrix $\left(\mathrm{HNO}_{3}\right.$ solution).

Leaching studies were also utilized for evaluation of the method by calculating the mass balance of leaching experiment. Briefly, solid residues from filter were transferred quantitatively to the known volume of $1 \%$ Triton X-100 solution. Next, they were sonicated to ensure good dispersion and measured using ICP-AES instrument. After that sum of the nickel determined in the leachate and nickel determined in the postleaching CNT slurries was compared with the total nickel concentration, determined by ICP-AES with slurry sample introduction.

2.3.6. Determination of Metals and Metal Oxides in Examined Hybrid Materials. Concentration of $\mathrm{Ce}, \mathrm{Zr}$, and $\mathrm{Ni}$ in $100 \mathrm{mg} \mathrm{L}^{-1}$ slurries of examined $\mathrm{Ni}-\mathrm{CeZrO}_{2} / \mathrm{CNT}, \mathrm{CeZrO}_{2} /$ $\mathrm{CNT}$, and $\mathrm{Ni} / \mathrm{CNT}$ hybrid materials was determined with ICP-AES method, with operating parameters given in Table 1. Standards for calibration were prepared in the range of 1$40 \mathrm{mg} \mathrm{L}^{-1}$ for Ce, 1-20 $\mathrm{mg} \mathrm{L}^{-1}$ for $\mathrm{Zr}$, and $0.5-20$ for $\mathrm{Ni}$.

\section{Results and Discussion}

3.1. Materials Characterization. In order to observe the micromorphology of studied materials SEM micrographs were taken (Figure 1). To present the differences in morphology of modified CNTs (Figures 1(b), 1(c), and 1(d)) the original, raw CNTs were also examined (Figure 1(a)).

Figure 1(a) presents raw CNTs, which are definitely much organized than MWCNTs dispersed and embedded in metal/metal oxide bulk, visible in Figures 1(b), 1(c), and 1(d). The chaotic arrangement of CNTs in these hybrid materials indicates good blending and the strong interfacial adhesion between the CNTs and inorganic additives. Additionally, the presence of metals and metal oxides in the studied materials
TABLE 2: Effect of slurry concentration on concentration of cerium, zirconium (calculated to metal oxide concentration), and nickel determined in $\mathrm{Ni}-\mathrm{CeZrO}_{2} / \mathrm{CNT}$ hybrid material.

\begin{tabular}{lccc}
\hline $\begin{array}{l}\text { Slurry concentration } \\
{\left[\mathrm{mg} \mathrm{L}^{-1}\right]}\end{array}$ & $\mathrm{CeO}_{2}[\%]$ & $\mathrm{ZrO}_{2}[\%]$ & $\mathrm{Ni}[\%]$ \\
\hline 40 & $21.36 \pm 0.18$ & $6.49 \pm 0.04$ & $9.80 \pm 0.15$ \\
100 & $21.23 \pm 0.14$ & $6.41 \pm 0.22$ & $9.83 \pm 0.18$ \\
200 & $21.00 \pm 0.14$ & $6.47 \pm 0.08$ & $9.81 \pm 0.17$ \\
400 & $20.57 \pm 0.43$ & $6.19 \pm 0.24$ & $9.71 \pm 0.42$ \\
\hline
\end{tabular}

was confirmed by the EDS analysis (Energy Dispersive X-ray Spectroscopy).

3.2. ICP-AES Sample Preparation. According to previously described protocol [10], the same dispersing agent, its concentration, and the conditions of ultrasonication were applied in this study. Effectiveness of homogenization method could be observed with the naked eye (Figures 2(a) and 2(b)). Obtaining a homogeneous black, well-dispersed slurry shows that homogenization method, utilized in these studies, was appropriate.

3.3. Effect of Slurry Concentration on Determination of Cerium, Zirconium, and Nickel. Optimal investigated material slurry concentration range must be selected because it constitutes important step in the overall analysis. Transport efficiency, atomization, and excitation in plasma depend on the number of particles in suspension. Too low slurry concentration may cause that only a small part of the particles will be introduced into the field of plasma. Similar problem may occur when slurries of higher concentrations are used and when the transportation of analyzed material can be affected by too many single particles in suspension. In addition, higher slurry concentrations may induce severe clogging of the supply tubes as well as nebulizer, which results in frequent cleaning necessity. High amounts of organic mass may also extinguish the plasma resulting in worsening its stability [12] and lowering its temperature [13]. These plasma parameters affect atomization and excitation efficiency of analytes and thus the results of the analysis. Therefore, the use of both too high and too low slurries concentration may result in obtaining false metal concentration.

In our previous work, we have proved that reliable and reproducible results are obtained for slurry concentration of 40 to $500 \mathrm{mg} \mathrm{L}^{-1}$ [10]. Therefore, in these studies, effect of slurry concentration on $\mathrm{Ce}, \mathrm{Zr}$, and $\mathrm{Ni}$ determination was examined in the range of 40 to $400 \mathrm{mg} \mathrm{L}^{-1}$ (Table 2).

Statistical analysis showed that in the examined range there were no statistically significant differences between the results obtained for various slurry concentrations (CochranCox test, 95\% confidence level, 3 replicates). Therefore, for the further examination, all slurry concentrations from the investigated range may be applied.

3.4. Effect of the RF Plasma Power on Determination of Cerium, Zirconium, and Nickel. Effect of the RF plasma 


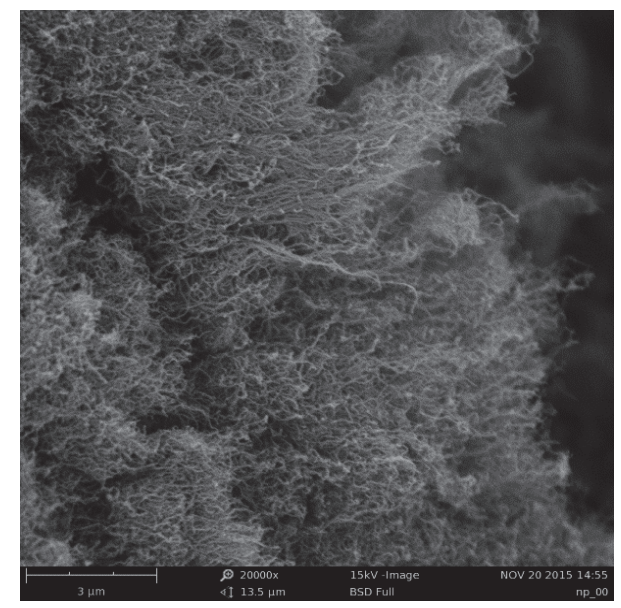

(a)

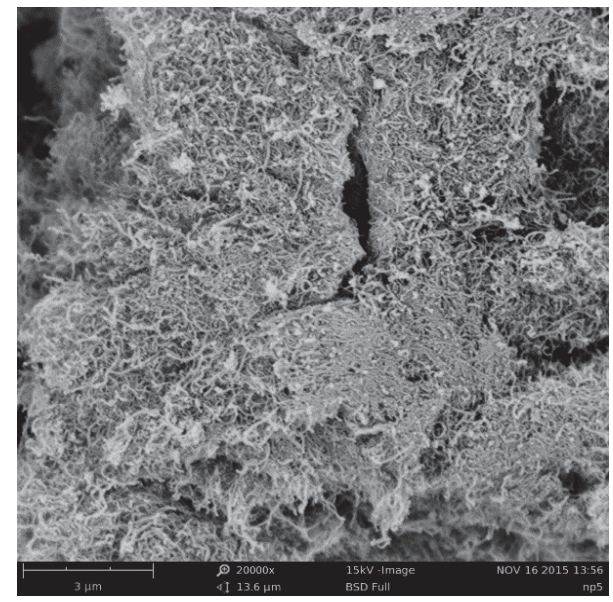

(c)

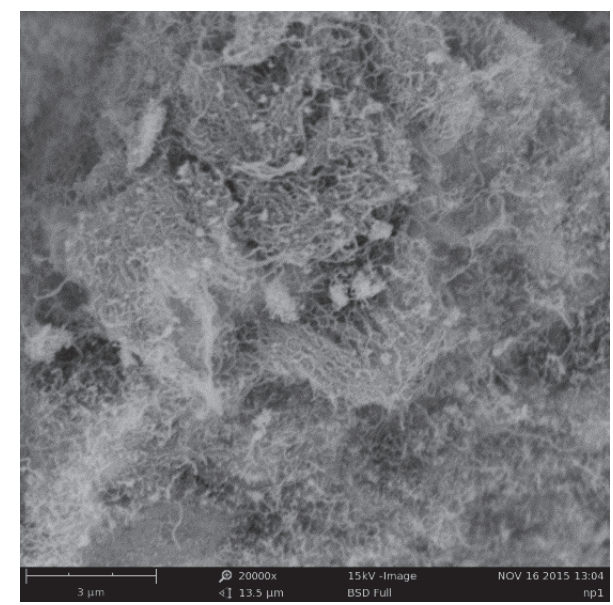

(b)

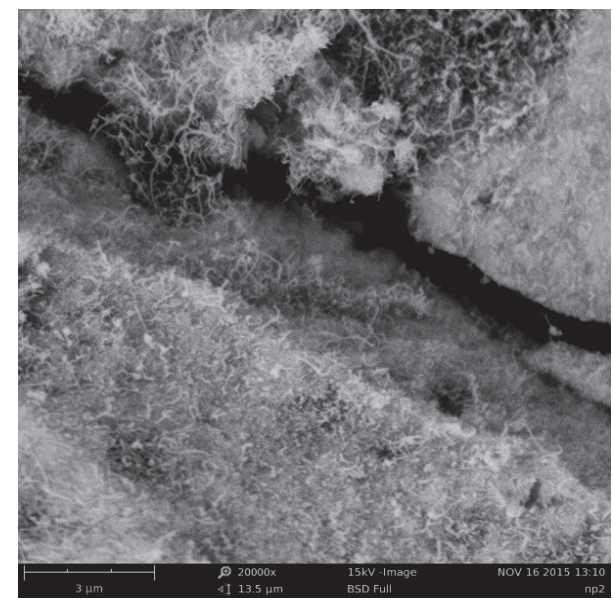

(d)

FIGURE 1: SEM micrographs of CNTs: (a) original; (b) modified with $\mathrm{Ni}$ and $\mathrm{CeZrO}_{2}$; (c) modified with Ni; and (d) modified with $\mathrm{CeZrO}_{2}$.

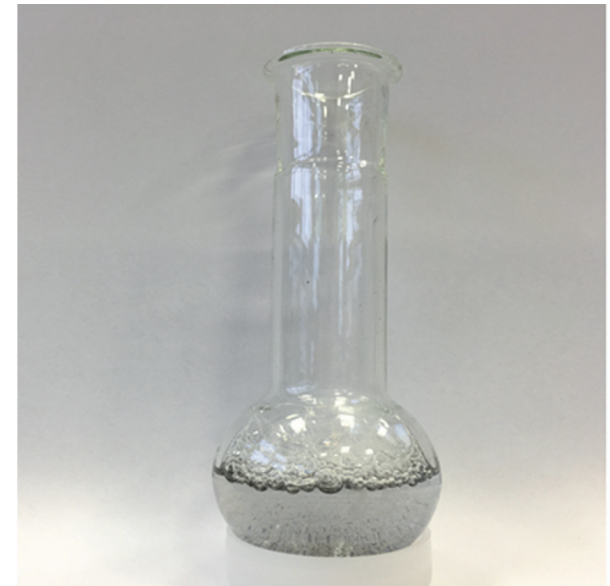

(a)

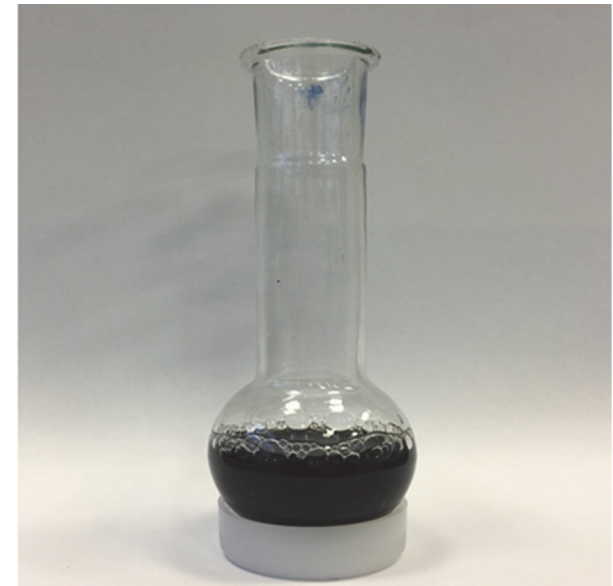

(b)

Figure 2: Slurries of examined materials $\left(\mathrm{CeZrO}_{2} / \mathrm{CNT}\right)$ : (a) before dispersion in Triton X-100 solution; (b) after dispersion in Triton X-100 solution with ultrasonication. 
TABLE 3: Effect of the RF power used for cerium, nickel, and zirconium determination in the $100 \mathrm{mg} \mathrm{L}^{-1}$ slurries of $\mathrm{Ni}-\mathrm{CeZrO}_{2} / \mathrm{CNT}$ hybrid material.

\begin{tabular}{lccc}
\hline RF power & $\mathrm{Ce}[\%]$ & $\mathrm{Ni}[\%]$ & $\mathrm{Zr}[\%]$ \\
\hline $1.2 \mathrm{~kW}$ & $17.08 \pm 0.09$ & $9.85 \pm 0.13$ & $4.70 \pm 0.03$ \\
$1.4 \mathrm{~kW}$ & $17.05 \pm 0.53$ & $9.80 \pm 0.29$ & $4.78 \pm 0.13$ \\
\hline
\end{tabular}

power on $\mathrm{Ce}, \mathrm{Zr}$, and $\mathrm{Ni}$ determination was also studied. Due to the fact that our previous experiment showed that increasing of RF plasma power did not extend the working range of slurry concentration [10], we decided to examine the effect of plasma power only for $100 \mathrm{mg} \mathrm{L}^{-1}$ slurries. Because the analytes used in this work are rather heavier ones, higher plasma temperature for standard measurements is recommended. Therefore $1.2 \mathrm{~kW}$ plasma power was selected as starting value to obtain the proper efficiency of $\mathrm{Ce}$ and $\mathrm{Zr}$ excitation. Next the effect of application of more powerful plasma (1.4 kW) was investigated (Table 3 ).

Generally, there are no significant differences between determination results when the $1.2 \mathrm{~kW}$ and $1.4 \mathrm{~kW}$ plasma power are used. However, in the case of plasma of $1.4 \mathrm{~kW}$, the precision of analysis, calculated as the confidence interval ( $95 \%$ confidence level, 3 replicates), is slightly lower. Moreover, $1.4 \mathrm{~kW}$ is the highest plasma power available for the spectrometer, while for routine work the lower RF plasma power is preferred. Therefore, in this study, $1.2 \mathrm{~kW}$ plasma power was chosen as an optimal value.

3.5. Leaching Studies. As mentioned above (Section 2.3.5) complete digestion of studied materials was impossible; therefore leaching studies were performed applying $5 \%$ and $67 \%$ nitric acid solutions. In all the cases, partial digestion of studied materials was observed, but clear solutions, without any material particles, were not obtained. Thus, after filtration, concentration of metals in the leachate was measured by ICP-AES technique, using standards prepared with appropriate matrix (nitric acid). Results are presented in Table 4. The highest leaching percentage (95\%) was obtained for nickel, when diluted nitric acid was utilized. In concentrated acid, amount of Ni leached into solution was significantly lower (about 77\%). This may be due to the fact that concentrated acid may cause partial passivation of the metal, thus affecting metal dissolution. In the case of $\mathrm{Ce}$ and $\mathrm{Zr}$ oxides poor leaching percentage (several\%) was obtained, almost independently from nitric acid concentration. Solubility of mentioned oxides strongly depends on their history (e.g., temperature of their production or aging processes $[14,15])$, so it is difficult to predict leaching effectiveness of such oxides and propose a universal leaching procedure.

Due to the fact that validation of the method cannot be conducted using a certified reference material, leaching studies were utilized for this purpose. Similarly to our earlier experiment [10] the evaluation of the method was performed by calculating mass balance during the leaching studies. Sum of the nickel determined in the leachate and nickel determined in the postleaching CNT slurries was compared with the total nickel concentration determined by ICP-AES

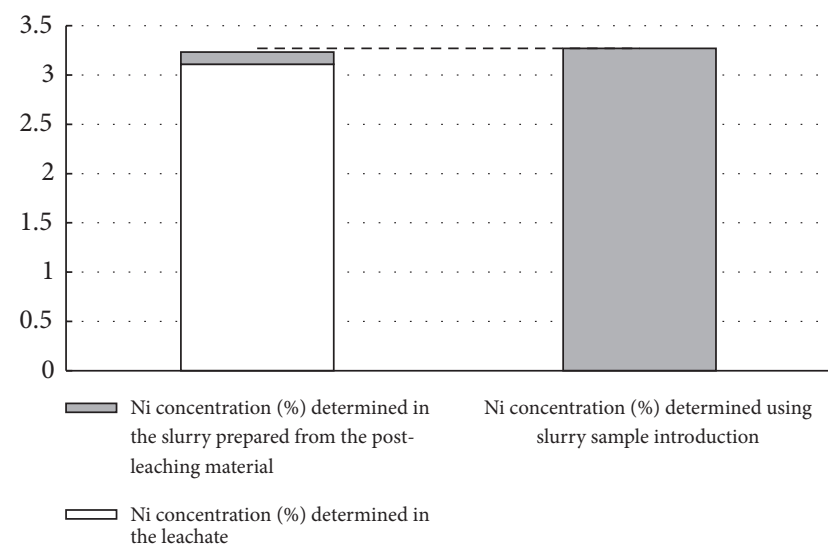

FIGURE 3: Mass balance of Ni in leaching studies (leaching medium-5\% $\mathrm{HNO}_{3}$ ).

with slurry sample introduction (Figure 3). This comparison showed that the calculated sum of nickel in leachate and postleaching CNTs was in good agreement with the total content of nickel determined by evaluated method. This proved the method to be applicable for hybrid CNT-based catalysts analysis.

3.6. Determination of Metals and Metal Oxides in CNTs Based Materials by the Slurry Sampling ICP-AES Technique. Based on the experiment described above, the following parameters were used to determine the concentration of metals and metal oxides in prepared catalysts samples: 30 min ultrasonication in Triton X-100 solution, $100 \mathrm{mg} \mathrm{L}^{-1}$ slurry concentration, and $1.2 \mathrm{~kW}$ plasma power. The results of analysis are presented in Table 5. In all cases precision of the method, evaluated as the confidence interval (95\% confidence level, 12 replicates), was high and did not exceed 3.5\% of the mean value. This proved that the precision of the proposed method in this study, ICP-AES slurry nebulization analysis, is high enough to be successfully applied for direct determination of metals included in hybrid CNT materials.

\section{Conclusions}

In our study, fast and simple ICP-AES slurry nebulization technique was proposed for direct determination of metals (cerium, zirconium, and nickel) in hybrid CNT-based materials ( $\mathrm{Ni}-\mathrm{CeZrO}_{2} / \mathrm{CNT}, \mathrm{CeZrO}_{2} / \mathrm{CNT}$, and $\mathrm{Ni} / \mathrm{CNT}$ ). Laborious and time-consuming sample preparation protocols have been replaced by fast and easy slurries preparation, thus shortening the analysis time. Leaching examination proved that the investigated materials are very difficult to digest/dissolve and the obtained leachate cannot be used to evaluate the metal content (only part of the metal is leached from the material). Optimal analysis parameters, such as slurry concentration and RF power, were established after examining their effect on the result. Generally, no significant effect of both RF power $(1.2$ and $1.4 \mathrm{~kW})$ and slurry concentration in the range of $40-400 \mathrm{mg} \mathrm{L}^{-1}$ was observed. In all of the cases, the precision of the proposed method did 
TABle 4: Leaching of Ce, $\mathrm{Zr}$, and $\mathrm{Ni}$ from hybrid Ni/CNT and $\mathrm{CeZrO}_{2} / \mathrm{CNT}$ materials (leaching medium-5\% and $67 \% \mathrm{HNO}_{3}$ ).

\begin{tabular}{|c|c|c|c|c|c|}
\hline \multirow[b]{2}{*}{$\mathrm{Me}$} & \multicolumn{2}{|c|}{$5 \% \mathrm{HNO}_{3}$} & \multicolumn{2}{|c|}{$67 \% \mathrm{HNO}_{3}$} & \multirow{2}{*}{$\begin{array}{c}\text { Me in } 1 \mathrm{~g} \text { of examined } \\
\text { material (slurry } \\
\text { nebulization ICP-AES) } \\
{[\mathrm{mg}]}\end{array}$} \\
\hline & $\begin{array}{c}\text { Me leached from } 1 \mathrm{~g} \\
\text { of examined material } \\
{[\mathrm{mg}]}\end{array}$ & Recovery [\%] & $\begin{array}{l}\text { Me leached from } 1 \mathrm{~g} \\
\text { of examined material } \\
{[\mathrm{mg}]}\end{array}$ & Recovery [\%] & \\
\hline \multicolumn{6}{|c|}{$\mathrm{CeZrO}_{2} / \mathrm{CNT}$} \\
\hline $\mathrm{Ce}$ & 23.88 & 12.91 & 7.91 & 4.28 & 184.92 \\
\hline $\mathrm{Zr}$ & 2.02 & 4.25 & 1.16 & 2.44 & 47.56 \\
\hline \multicolumn{6}{|c|}{$\mathrm{Ni} / \mathrm{CNT}$} \\
\hline $\mathrm{Ni}$ & 31.10 & 95.08 & 25.27 & 77.25 & 32.71 \\
\hline
\end{tabular}

TABLE 5: Content of $\mathrm{CeO}_{2}, \mathrm{ZrO}_{2}$, and $\mathrm{Ni}$ in the examined materials $(n=12)$. The remaining content is assumed to be carbon.

\begin{tabular}{lccc}
\hline & \multicolumn{3}{c}{ Mean value \pm confidence interval (\%) } \\
& $\mathrm{CeO}_{2}$ & $\mathrm{ZrO}_{2}$ & $\mathrm{Ni}$ \\
\hline $\mathrm{Ni}-\mathrm{CeZrO}_{2}$ & $21.04 \pm 0.24$ & $6.39 \pm 0.09$ & $9.79 \pm 0.10$ \\
$\mathrm{CeZrO}_{2}$ & $21.33 \pm 0.43$ & $6.51 \pm 0.23$ & - \\
$\mathrm{Ni}$ & - & - & $3.27 \pm 0.10$ \\
\hline
\end{tabular}

not exceed $3.5 \%$ of the mean value. Evaluation of the method was conducted by summing the metal content determined in the leachate and the metal content determined in the slurries of postleaching material; the result was in good agreement with the metal concentration determined directly, by the slurry nebulization ICP-AES technique. Therefore, the proposed method is the most appropriate method for direct $\mathrm{Ce}, \mathrm{Zr}$, and $\mathrm{Ni}$ determination in investigated hybrid materials. Additionally, it can be suitable for determination of other metals in different CNT-based materials.

\section{Competing Interests}

The authors declare that there is no conflict of interests regarding the publication of this paper.

\section{References}

[1] R. H. Baughman, A. A. Zakhidov, and W. A. de Heer, "Carbon nanotubes-the route toward applications," Science, vol. 297, no. 5582, pp. 787-792, 2002.

[2] A. Bianco, K. Kostarelos, and M. Prato, "Applications of carbon nanotubes in drug delivery," Current Opinion in Chemical Biology, vol. 9, no. 6, pp. 674-679, 2005.

[3] A. Bianco, K. Kostarelos, C. D. Partidos, and M. Prato, "Biomedical applications of functionalised carbon nanotubes," Chemical Communications, no. 5, pp. 571-577, 2005.

[4] V. Popov, "Carbon nanotubes: properties and application," Materials Science and Engineering: R: Reports, vol. 43, no. 3, pp. 61-102, 2004.

[5] P. Serp, "Carbon nanotubes and nanofibers in catalysis," Applied Catalysis A: General, vol. 253, no. 2, pp. 337-358, 2003.

[6] Y. Zhang, H. Zhang, G. Lin, P. Chen, Y. Yuan, and K. Tsai, "Preparation, characterization and catalytic hydroformylation properties of carbon nanotubes-supported Rh-phosphine catalyst," Applied Catalysis A: General, vol. 187, no. 2, pp. 213-224, 1999.

[7] E. O. Jardim, M. Gonçalves, S. Rico-Francés, A. SepúlvedaEscribano, and J. Silvestre-Albero, "Superior performance of multi-wall carbon nanotubes as support of Pt-based catalysts for the preferential CO oxidation: effect of ceria addition," Applied Catalysis B: Environmental, vol. 113-114, pp. 72-78, 2012.

[8] C. Wang, B. Li, H. Lin, and Y. Yuan, "Carbon nanotubesupported Pt-Co bimetallic catalysts for preferential oxidation of $\mathrm{CO}$ in a $\mathrm{H} 2$-rich stream with $\mathrm{CO} 2$ and $\mathrm{H} 2 \mathrm{O}$ vapor," Journal of Power Sources, vol. 202, pp. 200-208, 2012.

[9] R. Zeisler, R. L. Paul, R. Oflaz Spatz et al., "Elemental analysis of a single-wall carbon nanotube candidate reference material," Analytical and Bioanalytical Chemistry, vol. 399, no. 1, pp. 509517, 2011.

[10] J. Bok-Badura, A. Jakóbik-Kolon, M. Turek, S. Boncel, and K. Karoń, "A versatile method for direct determination of iron content in multi-wall carbon nanotubes by inductively coupled plasma atomic emission spectrometry with slurry sample introduction," RSC Advances, vol. 5, no. 123, pp. 101634101640, 2015.

[11] P. Randhawa, J.-S. Park, S. Sharma, P. Kumar, M.-S. Shin, and S. S. Sekhon, "Effect of surfactant (Triton X-100) concentration on dispersion and functionalization of multiwall carbon nanotubes," Journal of Nanoelectronics and Optoelectronics, vol. 7, no. 3, pp. 279-286, 2012.

[12] G. A. Zachariadis and C. E. Michos, "Development of a slurry introduction method for multi-element analysis of antibiotics by inductively coupled plasma atomic emission spectrometry using various types of spray chamber and nebulizer configurations," Journal of Pharmaceutical and Biomedical Analysis, vol. 43, no. 3, pp. 951-958, 2007.

[13] S. T. Sparkest and L. Ebdont, "Direct atomic spectrometric analysis by slurry atomisation. Part 6 . Simplex optimisation of a direct current plasma for kaolin analysis," Journal of Analytical Atomic Spectrometry, vol. 3, no. 4, pp. 563-569, 1988.

[14] S. Jaenicke, G. K. Chuah, V. Raju, and Y. T. Nie, "Structural and morphological control in the preparation of high surface area zirconia," Catalysis Surveys from Asia, vol. 12, no. 3, pp. 153-169, 2008.

[15] J. W. Mellor, A Comprehensive Treatise on Inorganic and Theoretical Chemistry, Wiley, New York, NY, USA, 1964. 

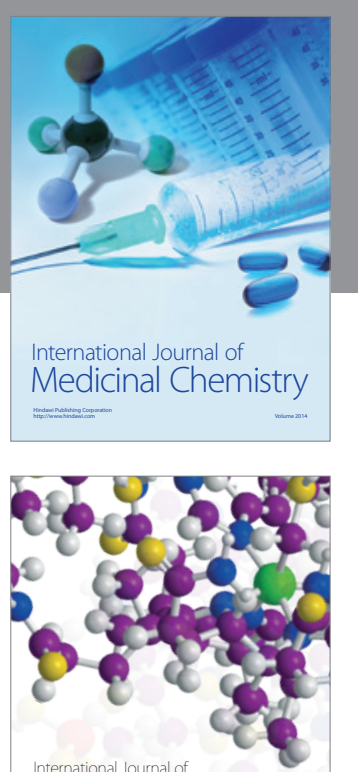

Carbohydrate Chemistry

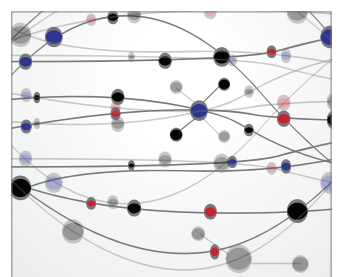

The Scientific World Journal
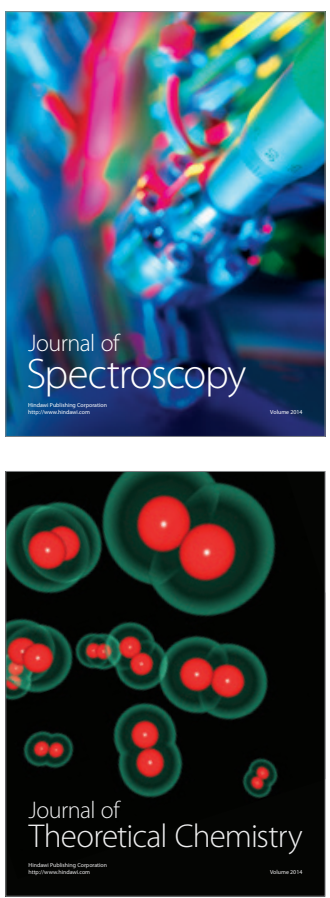
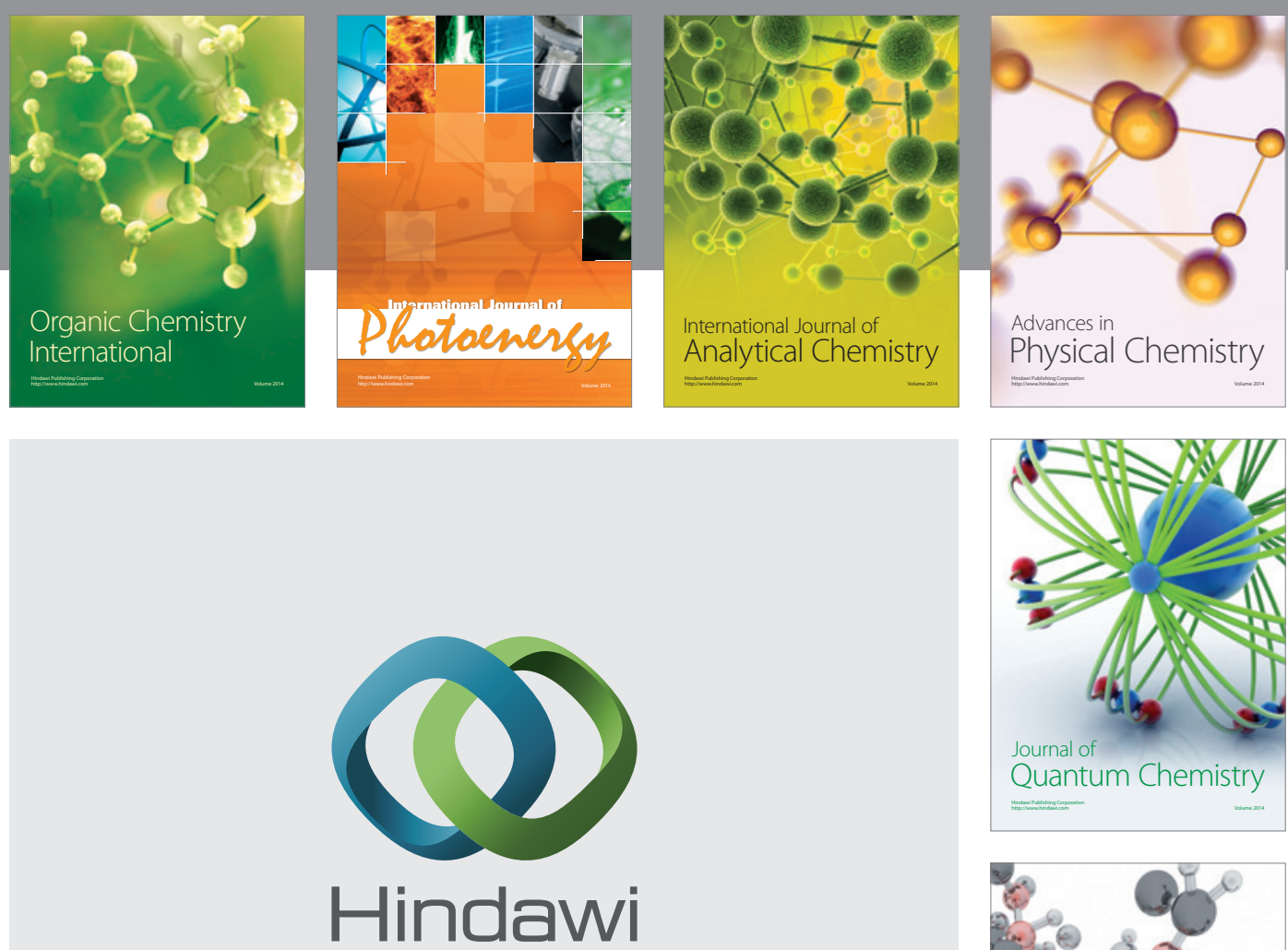

Submit your manuscripts at

https://www.hindawi.com

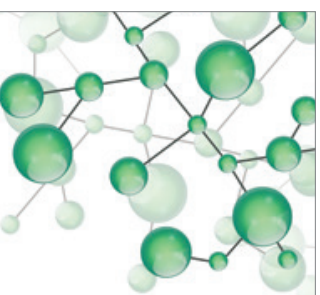

International Journal of

Inorganic Chemistry
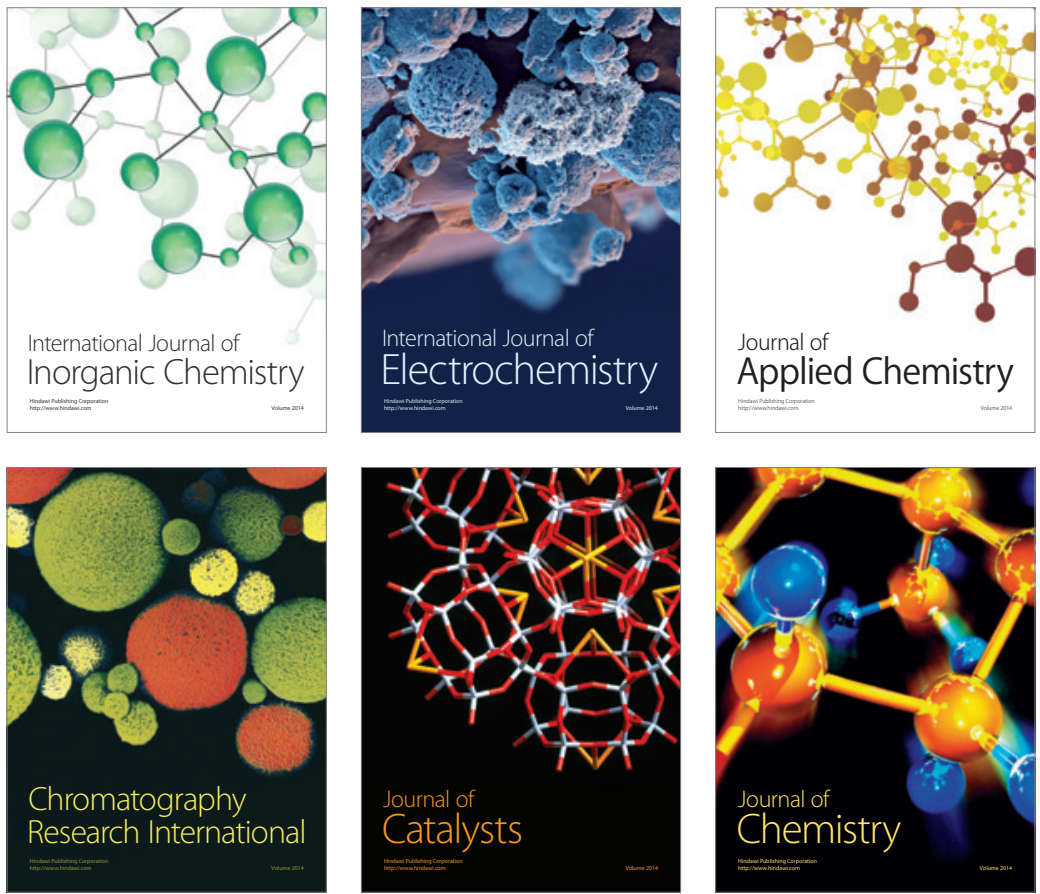

Journal of

Applied Chemistry
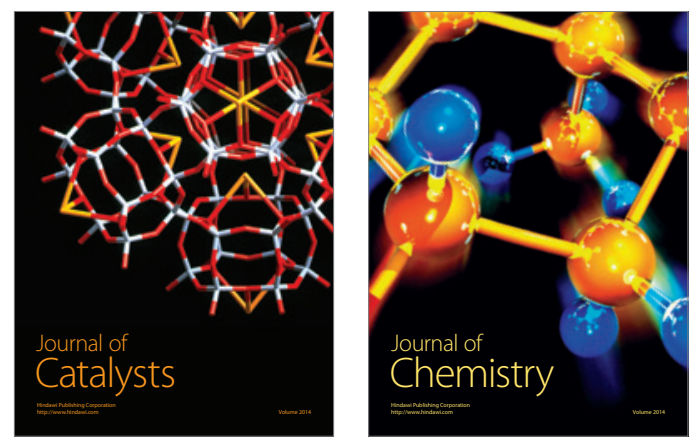
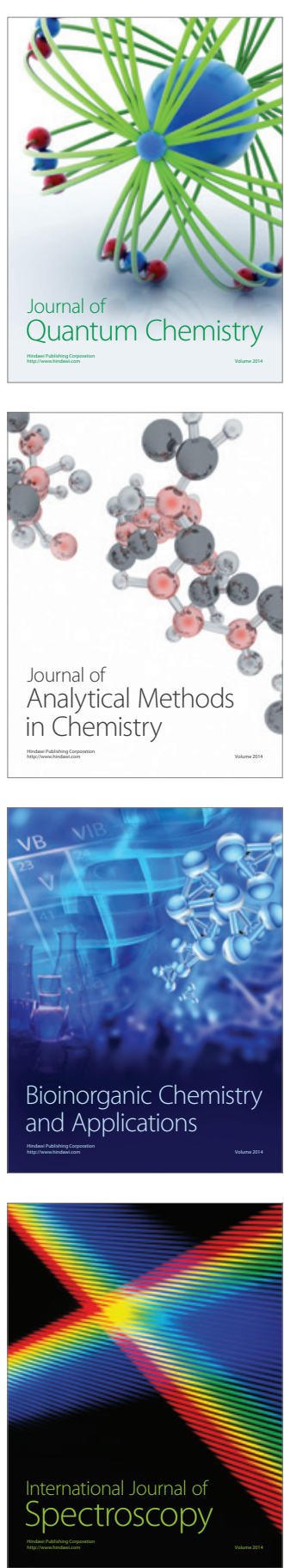